\title{
Birth weight at term and lung function in adolescence: no evidence for a programmed effect
}

\author{
Jean W A Matthes, P A Lewis, D P Davies, Jaqueline A Bethel
}

\begin{abstract}
It has been suggested that factors which influence low birth weight at term may be associated with reduced lung function in later life. This hypothesis was investigated in a comparative (retrospective) cohort study of 164 matched pairs of subjects where the observers responsible for tracing and studying the subjects were unaware of their case or control status. The subjects, born in Cardiff between 1975 and 1977, were of mean age $15 \cdot 7$ years. Cases (low birth weight $(<2500 \mathrm{~g})$ at term) were matched with controls (normal birth weight $(3000-3800 \mathrm{~g})$ at term) for sex, parity, place of birth, date of birth, and gestation. Lung function was measured using a portable spirometer.

The corrected mean differences $(95 \%$ confidence interval) in forced vital capacity (FVC) and flow when $50 \%$ or $25 \%$ of the FVC remains in the lungs between the cases and controls were respectively $-41 \mathrm{ml}(-140$ to 58$),-82 \mathrm{ml} / \mathrm{sec}(-286$ to 122), and $-83 \mathrm{~m} / \mathrm{sec}(-250$ to 83$)$. None of these differences were statistically significant. These results are inconsistent with the hypothesis that low birth weight at term is associated with reduced lung function in adolescence.

(Arch Dis Child 1995; 73: 231-234)
\end{abstract}

Keywords: lung function, intrauterine growth retardation, programming hypothesis.

A hypothesis has been advanced that programming of physiological or metabolic events by undernutrition at critical periods early in development may lead to long term changes that eventually manifest in disease. ${ }^{1}$ One such example is reduced lung function and chronic obstructive airways disease resulting from an adverse intrauterine environment causing permanent alteration in structure or function of the lungs. ${ }^{23}$ The division of the airways is complete by 18 weeks' gestation. ${ }^{4}$ Thereafter there is no significant further increase in airway number, growth taking place by an increase in airway length and diameter and elaboration of the terminal alveoli. It is plausible therefore that anything that impairs division of the airways in fetal life might 'program' altered lung function, and be a risk factor for lung disease in later life. We report lung function in 15 year old adolescents born at term of either low or normal birth weight as a further investigation of the programming hypothesis.
Subjects and methods

This is a secondary analysis of a comparative retrospective study where the two trained field workers were blind to the case-control status of the subjects. The subjects were identified from the Cardiff birth survey. Details of the study protocol including calculation of sample size, identification and matching of cases and controls, and tracing of subjects have been described in detail previously. ${ }^{5}$ Briefly, the study was designed to detect a difference between the two groups of one third of a standard deviation with an $\alpha$ of 0.05 and a $\beta$ of $0 \cdot 10$. This cohort was born between 1 September 1975 and 31 July 1977. The cases were born at 38 weeks' gestation or more and weighed less than $2500 \mathrm{~g}$; as a group they were considered to have suffered intrauterine growth retardation. The controls weighed $3000-3800 \mathrm{~g}$ at birth and were considered to have been adequately grown in utero. Cases and controls were matched for sex, parity, age, and hospital of delivery as a proxy for social class. They were all closely matched for gestational age.

The study protocol specified four measures of lung function: (1) forced vital capacity (FVC), a frequently measured index related to the size of the lungs ${ }^{6}$; (2) forced expiratory volume in one second $\left(\mathrm{FEV}_{1}\right)$, an index related to large airway size; (3) flow when $50 \%$ of the FVC remains in the lungs (F50); and (4) flow when $25 \%$ of the FVC remains in the lungs (F25). ${ }^{7}$

F50 and F25 were chosen as parameters of small airway function. $\mathrm{FEV}_{1}$, though widely used in clinical practice, has limitations in young children because of a tendency to exhale the total FVC in less than one second. ${ }^{8} \mathrm{~A}$ literature search provided no guidance on whether a similar problem would be expected in adolescents.

The subjects were visited at home by an observer trained in anthropometry and the measurement of lung function. A questionnaire was administered relating to previous and current respiratory illness, occupation of the chief wage earner in the household, and smoking habits of parents and subject. With the subject lightly clothed and without shoes, weight was measured to the nearest $100 \mathrm{~g}$ using a portable Soenle scale. Height was measured using a Harpenden portable stadiometer to the nearest $1 \mathrm{~mm}$. Measurements of lung volume and airway flow were performed using a Microlab 3000 portable spirometer, resolution $10 \mathrm{ml}$, with an attached printout. ${ }^{9}$ The results are output in numerical form on paper with no subsequent calculations required. The data are also presented as graphs 
Table 1 Characteristics of cases and controls

\begin{tabular}{lcc}
\hline & $\begin{array}{c}\text { Cases } \\
(n=165)\end{array}$ & $\begin{array}{l}\text { Controls } \\
(n=165)\end{array}$ \\
\hline Sex (M/F) & $63 / 102$ & $63 / 102$ \\
Mean birth weight in $\mathrm{g}$ & 2250 & 3300 \\
Mean (SD) age in years & $15 \cdot 6(0 \cdot 77)$ & $15 \cdot 8(0 \cdot 84)$ \\
Mean (SD) height in cm & $160 \cdot 7(7 \cdot 7)$ & $166 \cdot 1(8 \cdot 0)$ \\
Mean (SD) weight in kg & $52 \cdot 1(9 \cdot 0)$ & $58 \cdot 4(1 \cdot \cdot)$ \\
\hline
\end{tabular}

of flow/volume and volume/time which are used to aid detection of subject errors in technique.

The procedure for performing a FVC manoeuvre was demonstrated to the subject. After a few practice blows, three reproducible blows (defined as a FVC within $10 \%$ of the maximal FVC) were produced. The subjects were encouraged to perform these tests to the best of their ability. Measurements were taken with the subject seated and without using a noseclip. Graphs which showed hesitancy or cough were not used in the analysis. Of the acceptable recordings for each subject, the one which showed the largest FVC was used to extract the data.

The results were given at body temperature and pressure and fully saturated with water. The data were analysed using the statistical package SPSS/PC. ${ }^{10}$ Means were compared using a paired $t$ test.

Results

One hundred and sixty five out of $222(74 \cdot 3 \%)$ of the case-control pairs participated in the study. The cases and controls are described in table 1. Cases and controls were matched for gestation to the nearest week (158 pairs). In four cases gestation was one week longer than the controls and in three controls gestation was one week longer than the cases. Parity was matched exactly in 158 of the pairs. Social class during pregnancy (as recorded on the Cardiff birth survey) was lower for cases than for controls. Of those seen, $25 \%$ of cases and $37 \%$ of controls were in social classes 1 and 2 . The cases and their parents smoked more than the controls (table 2). During pregnancy 59\% of mothers of cases smoked compared with $39 \%$ of mothers of controls. Asthma was reported in 24/165 cases and 24/162 controls. Satisfactory lung function recordings were obtained in all but one subject. Weight was not recorded in one subject. Therefore two casecontrol pairs could not be used in the analysis.

For 61 cases and 46 controls the total FVC was expired in less than one second. $\mathrm{FEV}_{1}$ was therefore not used in the analysis. The unadjusted lung function results are shown in table 3.

Table 2 Comparison between the cases and controls current smoking habits ( $n=165$ pairs)

\begin{tabular}{|c|c|c|c|c|}
\hline & \multicolumn{2}{|l|}{ Cases } & \multicolumn{2}{|l|}{ Controls } \\
\hline & $\begin{array}{l}\text { No who } \\
\text { smoke }\end{array}$ & $\begin{array}{l}\text { Total cigarettes smoked } \\
\text { daily (mean No/person) }\end{array}$ & $\begin{array}{l}\text { No who } \\
\text { smoke }\end{array}$ & $\begin{array}{l}\text { Total cigarettes smoked } \\
\text { daily (mean No/person) }\end{array}$ \\
\hline $\begin{array}{l}\text { Subjects } \\
\text { Mothers } \\
\text { Fathers }\end{array}$ & $\begin{array}{l}34 \\
65 \\
53\end{array}$ & $\begin{array}{c}317(9 \cdot 3) \\
1472(22 \cdot 6) \\
1008(19 \cdot 0)\end{array}$ & $\begin{array}{l}27 \\
53 \\
34\end{array}$ & $\begin{array}{l}280(10 \cdot 4) \\
876(16 \cdot 5) \\
603(17 \cdot 7)\end{array}$ \\
\hline
\end{tabular}

There were important differences in age, height, and weight between cases and controls which were expected to influence FVC, F50, and F25. The data was adjusted for these differences by constructing linear regression models. FVC, F25, and F50 were estimated using age, height, weight, body mass index, and case-control status as independent variables. The models were built using stepwise multiple regression. The best fit to the data were the following equations:

$$
\begin{gathered}
\text { FVC }=0.44 \times \text { height }(\mathrm{m})+0.15 \times \text { weight }(\mathrm{kg}) \\
+7.87 \times \text { age }(\text { years }) \\
r^{2}=0.59 \\
\begin{array}{c}
\text { F5 }=0.23 \times \text { height }(\mathrm{m})+20.1 \times \text { age }(\text { years }) \\
+0.18 \times \text { weight }(\mathrm{kg}) \\
r^{2}=0.18 \\
\text { F25 }=0.25 \times \text { height }(\mathrm{m})+16.9 \times \text { age (years }) \\
r^{2}=0.10
\end{array}
\end{gathered}
$$

The differences in height, weight, and age between the cases and controls were used to adjust the differences in FVC, F50, and F25. The corrected differences ( $95 \%$ confidence interval (CI)) in FVC, F25, and F50 between the cases and controls were respectively $-41 \mathrm{ml}$ ( -140 to 58$),-82 \mathrm{ml} / \mathrm{sec}$ ( -286 to 122 ), and $-83 \mathrm{ml} / \mathrm{sec}(-250$ to 83 ) (table 4$)$. None of these differences were statistically significant.

The variables of social class, smoking habits of subjects, and current and pregnancy smoking habits of mothers were not adjusted for in the regression analysis. As all of these factors were expected to be associated with reduced lung function and showed a higher prevalence in the cases, not adjusting for these variables introduced a bias against the null hypothesis.

\section{Discussion}

Certain changes in the intrauterine environment are known to influence lung development. Extreme examples include oligohydramnios ${ }^{11} 12$ and reduced fetal breathing movements ${ }^{13-15}$ associated with pulmonary hypoplasia and larygeal atresia causing pulmonary hyperplasia. ${ }^{16}$ Congenital diaphragmatic hernia is associated with reduced numbers of conducting airways, bronchioli, and alveoli ${ }^{17-19}$ possibly due to pressure on the developing lung. Once the defect is repaired abnormalities of lung function persist, and postmortem data have shown that the conducting airways and bronchioli remain reduced in number while the alveoli increase in size. ${ }^{20}$ Anatomical studies of

Table 3 Lung function data uncorrected for age and body size ( $n=164$ pairs)

\begin{tabular}{lrrrl}
\hline & Mean (SD) & Median & Minimum & Maximum \\
\hline FVC (I) & & & & \\
Cases & $3.24(0.65)$ & 3.12 & 1.43 & 5.57 \\
Controls & $3.61(0.74)$ & 3.50 & 2.00 & 6.28 \\
Difference & $-0.37(0.79)$ & -0.36 & -2.94 & 1.47 \\
F50 (1/sec) & & & & \\
Cases & $4.35(1.03)$ & 4.25 & 2.18 & 7.26 \\
Controls & $4.71(1.18)$ & 4.60 & 2.14 & $8 \cdot 46$ \\
Difference & $-0.36(1.37)$ & -0.32 & -3.92 & 3.78 \\
F25 (1/sec) & $2.62(0.83)$ & 2.50 & 1.22 & 5.76 \\
Cases & $2.87(0.88)$ & 2.74 & 0.94 & 5.62 \\
Controls & 2.87 & \\
Difference & $-0.25(1.09)$ & -0.30 & -0.43 & 3.38 \\
\hline
\end{tabular}


Table 4 Difference in age/size adjusted lung function parameters between cases and controls ( $n=163$ pairs)

\begin{tabular}{|c|c|c|c|c|c|c|c|}
\hline & Mean (SD) & Median & Minimum & Maximum & $S E$ & $\begin{array}{l}\text { Two tail } \\
\text { probability }\end{array}$ & $95 \% C I$ \\
\hline $\begin{array}{l}\text { Adjusted difference in FVC }(\mathrm{ml}) \\
\text { Adjusted difference in F50 (ml/sec) } \\
\text { Adjusted difference in F25 (ml/sec) }\end{array}$ & $\begin{array}{l}-41(637) \\
-82(1304) \\
-83(1065)\end{array}$ & $\begin{array}{r}-24 \\
-181 \\
-152\end{array}$ & $\begin{array}{l}-1600 \\
-3020 \\
-4165\end{array}$ & $\begin{array}{l}1450 \\
3526 \\
3257\end{array}$ & $\begin{array}{r}49 \cdot 6 \\
102 \cdot 0 \\
83 \cdot 0\end{array}$ & $\begin{array}{l}0 \cdot 40 \\
0 \cdot 42 \\
0 \cdot 32\end{array}$ & $\begin{array}{l}-140 \text { to } 58 \\
-286 \text { to } 122 \\
-250 \text { to } 83\end{array}$ \\
\hline
\end{tabular}

the lungs of a small number of intrauterine growth retarded infants have shown a reduction in the number of terminal airways. ${ }^{21}$

Our study does not suggest any link between low birth weight at term, a marker for an adverse intrauterine environment, and lung function in adolescence. This is the first reported study examining the influence of the intrauterine environment on lung function which has adjusted for gestational age in the study design. A more targeted adjustment of the birthweight classes to account for other known factors influencing birth weight, ethnic origin, and parity 22 were unimportant (nearly all subjects were of Welsh/European origin) or adjusted for in the study design. Published models give good fits but only for the mean values of the dependent variable. ${ }^{23}$

Our study cannot be directly compared with other studies with uncertain periods of gestation. Other studies have used different parameters of lung function. Thus in a study of Hertfordshire men aged 59-70 years, which associated impaired lung function with low birth weight, no mention was made of gestation and $\mathrm{FEV}_{1}$ was the main outcome measure. ${ }^{2}$ Mean FEV $_{1}$ (corrected for current height and age) rose by $0.061(95 \%$ CI 0.02 to 0.09 ) for each pound increase in birth weight. These results were independent of smoking habit and current social class. These babies were born between 1911 and 1943 and it was not until the mid-1970s that accurate methods of gestational assessment of newborn babies became available. ${ }^{24}$ It is possible that these indices of reduced lung function might relate more to premature delivery than to intrauterine growth retardation.

Regression analysis on our data showed that age, height, and weight were statistically important predictors of lung function. Previous longitudinal and cross sectional studies of lung function do not include weight so the existing published models are inadequate for our data. ${ }^{232526}$ Evidence suggests that if age, sex, and weight are used as explanatory factors for variations in lung function then pubertal stage provides no additional explanatory data. ${ }^{27}$ Thus even if there were differences in the pubertal stage between the cases and the controls this would have been adjusted for in our regression analysis, so that 'perturbation' of lung function due to adolescence cannot be invoked as a mechanism to explain the lack of effect of low birth weight on lung function. There must also be some concern about the applicability of population based regression data to our study subpopulation where $50 \%$ of the cases were drawn from one extreme of the birthweight distribution.

Reduced lung function has been well documented in 7 year old children who were born preterm. Significantly reduced expiratory flow indices (forced expiratory volume in 0.75 seconds $\left.\left(\mathrm{FEV}_{0.75}\right), \mathrm{F} 50, \mathrm{FEV}_{0.75} / \mathrm{FVC}\right)$ have been shown compared with a reference population, ${ }^{8}$ this being independent of neonatal respiratory illness. There was no difference in FVC between the two groups. Birth weight adjusted for gestational age has been found to be significantly associated with $\mathrm{FEV}_{1}$ $(p<0.001)$ and FVC $(p<0.01)$ in children aged 5-11 years. ${ }^{28}$ However, $\mathrm{FEV}_{1}$ is an unreliable index of flow ${ }^{8}$ in children of this age. Children of low birth weight tend to be smaller and smaller children may be more likely to complete the measure in less than one second. Thus children who were of low birth weight may have results which are too small and the reported statistically significant association may be due to a systematic bias. This source of bias could have been investigated by a stratified analysis. The other expiratory flow measures listed in the study (the forced expiratory flow between $75 \%$ and $85 \%$ and between $25 \%$ and $75 \%$ of the FVC) did not produce any association with adjusted birth weight.

Studies which rely on cohorts born many years ago when infant mortality was high ${ }^{2}$ also have the potential for survivor bias. Several studies have questioned the possibility whether the association between low birth weight and later disease might be explained by confounding introduced by a continuum of disadvantage, ${ }^{29-31}$ the effects of which might not yet be apparent in the 15 year old adolescents in our study. Factors which determine lung volume and maximal air flow in adult life have their major influence before 6 years. ${ }^{32}$ Lung function tracks well with tracking coefficients for $\mathrm{FEV}_{1}$ and FVC for children aged $6-11$ years of 0.86 and 0.90 respectively for girls and 0.95 and 0.93 respectively for boys. ${ }^{33} 34$ This suggests that by the age of 15 years the lung function indices derived from the subjects in our study are unlikely to be significantly deflected subsequently by any prenatal influence. Any future deviation that might occur would therefore be more likely to be due to environmental factors such as smoking habit, working environment, or disease.

The possibility of a 'false negative' result should not be discounted. However, our methodology sought to minimise the effects of control selection and ascertainment bias by blinding the field workers attempting to trace the subjects to their case-control status. Cases had a lower social class and higher subject and parental smoking habits. Not correcting for these factors has led to a greater underestimate in lung function in the cases compared with the controls. Thus these results would overestimate the strength of any effect.

The strength of this study is that it is based on a well defined geographical location, every 
member of the population having being recorded. The effective population studied here is over 9000 with only the most extreme cases being studied.

\section{Conclusion}

No association was demonstrated between birth weight at term and FVC, F25, or F50 at the age of 15 years. These findings do not support the hypothesis that an adverse intrauterine environment associated with low birth weight predisposes to impaired lung function and chronic obstructive airways disease in later life.

This study was supported by a grant from Children Nationwide. We thank the steering committee of the Cardiff Birth Survey for the use of the data. Mrs D Savory conducted much of the fieldwork. We are also grateful for the willing cooperation of all of the subjects.

1 Barker DJP. Fetal and infant origins of adult disease. London: British Medical Journal, 1992.

2 Barker DJP, Osmond C, Law CM. The intra-uterine and early postnatal origins of cardiovascular disease and chronic bronchitis. $¥$ Epidemiol Community Health 1989; 43: 237-40.

3 Barker DJP, Godfrey KM, Fall C, Osmond C, Winter PD, Shaheen SO. Relation of birth weight and childhood respiratory infection to adult lung function and death from chronic obstructive airways disease. BMF 1991; 303: 671-5.

4 Bucher U, Reid L. Development of the intrasegmental bronchial tree: the pattern of branching and development of cartilage at various stages of intra-uterine life. Thorax 1961; 16: 207-25.

5 Matthes JWA, Lewis PA, Davies DP, Bethel JA. The relationship between birth weight at term and systolic blood pressure in adolescence. $B M \Im \mathcal{F} 1994 ; 308$ : 1074-7.

6 Cotes JE. Lung function assessment and application in medicine. 5th Ed. Oxford: Blackwell Scientific Publications, 1993

7 Zapletal A, Motoyama EK, Gibson LE, Bouhys A. Pulmonary mechanics in asthma and cystic fibrosis. Pediatrics 1971; 48: 64-72.

8 Chan KN, Noble-Jamieson CM, Elliman A, Bryan EM, Silverman M. Lung function in children of low birth Silverman M. Lung function in children
weight. Arch Dis Child 1989; 64: 1284-93.

9 Gunawardena KA, Houston K, Smith AP. Evaluation of the turbine pocket spirometer. Thorax 1987; 42: 689-93.

10 Norusis MJ. SPSS/PC. +4.0. Base manual. Chicago: SPSS Inc, 1990 .

11 Hislop A, Hey E, Reid L. The lungs in congenital bilateral renal agenesis and dysplasia. Arch Dis Child 1979; 54: 32-8.

12 Wigglesworth JS, Desai R, Guerrini P. Fetal lung hypoplasia: biochemical and structural variations and their possible significance. Arch Dis Child 1981; 56: 606-15.

13 Alcorn D, Adamson TM, Maloney JE. Morphological effect of chronic bilateral phrenicectomy or vagotomy in the of chronic bilateral phrenicectomy or
fetal lamb. $\mathcal{F}$ Anat 1980; 130: 683-95.

14 Wigglesworth JS, Desai R. Effects on lung growth of cervical cord section in the rabbit fetus. Early Hum Dev 1979; 3: 51-65.
15 Boddy K, Dawes GS, Fisher R, Pinter S, Robinson JS. Fetal respiratory movements, electrocortical and cardiovascular responses to hypoxaemia and hypercapnia in sheep. $f$ Physiol (Lond) 1974; 243: 599-618.

16 Wigglesworth JS, Desai R, Hislop AA. Fetal lung growth in congenital laryngeal atresia. Pediatr Pathol 1987; 7: 515-25.

17 Silver MM, Thurston WA, Patrick JE. Perinatal pulmonary hyperplasia due to laryngeal atresia. Hum Pathol 1988; 19: $110-3$.

18 Kitigawa M, Hislop A, Boyden EA. Lung hypoplasia in congenital diaphragmatic hernia. A quantitative study of airway, artery and alveolar development. Br $\mathcal{F}$ Surg 1971 ; 58: $342-6$.

19 George DK, Cooney TP, Chiu BK. Hypoplasia and immaturity of the terminal lung unit (acinus) in congenital diaphragmatic hernia. Am Rev Respir Dis 1987; 136: 947-50.

20 Hislop A, Reid L. Persistent hypoplasia after repair of congenital diaphragmatic hernia. Thorax 1976; 31: 450-5.

21 Beddoes L, Howard CB, Sibbons PD, van Velzen D. Terminal duct number in unexplained cot death (SIDS) victims in comparison to airways of infants with intrauterine growth retardation (IUGR) and normal controls. Proceedings of the Third European Congress for the European Society for the Study and Prevention of Infant Deaths. Oxford, 1993: 37.

22 Wilcox M, Gardosi J, Mongelli M, Ray C, Johnson I. Birth weight from pregnancies dated by ultrasonography in a
multicultural British population. $B M \mathcal{F} 1993 ; 307: 588-91$.

23 Rosenthal M, Cramer D, Helms P, Denison D, Bush A, Warner JO. Lung function in white children aged 4 to 19
years: 1 - spirometry. Thorax 1993; 48: 794-802.

24 Dubowitz LMS, Dubowitz V, Goldberg C. Clinical assessment of gestational age in the newborn infant. $\mathcal{f}$ Pediatr 1970; 77: $1-10$.

25 Wang X, Dockery DW, Wypij D, Fay ME, Ferris BG. Pulmonary function between 6 and 18 years of age. Pediatr Pulmonol 1993; 15: 75-88.

26 Borsboom GJM, Van Pelt WV, Quanjer PH. Pubertal growth curves of ventilatory function: relationship with childhood respiratory symptoms. Am Rev Respir Dis 1993; 147: 372-8.

27 Baxter-Jones ADG, Helms P, Preece M, et al. Independent effects of physical growth and pubertal development on lung function Proceedings of the British Paediatric Association Annual Meeting 1994; 66: G193.

28 Rona RJ, Gulliford MC, Chinn S. Effects of prematurity and intrauterine growth retardation on respiratory health and intrauterine growth retardation on respiratory health

29 Elford J, Whincup P, Shaper AG. Early life experiences and adult cardiovascular disease: longitudinal and caseadult cardiovascular disease: longitudinal and

30 Ben-Shlomo Y, Davey Smith G. Deprivation in infancy or adult life; which is more important for mortality risk? Lancet 1991; 337: 530-4.

31 Davies DP, Matthes JWA. Fetal and infant growth and impaired glucose tolerance [Letter]. $B M \mathcal{F}$ 1991; 303: 1474.

32 Martin TR, Feldman HA, Fredberg J, Castile RG, Mead J, Beck Wohl ME. Relationship between maximal expiratory flows and lung volumes in growing humans. 7 Appl Physiol 1988; 65: 822-8.

33 Dockery DW, Berkey CS, Ware JH, Speizer FE, Ferris BG. Distribution of forced vital capacity and forced expiratory volume in one second in children 6 to 11 years of age. $\mathrm{Am}$ Rev Respir Dis 1983; 128: 405-12.

34 Lebowitz MD, Holdberg CJ, Knudson RJ, Burrows B. Longitudinal study of pulmonary development in childhood, adolescence, and early adulthood. Am Rev Respir Dis 1987; 136: 69-75. 